$\therefore$ is

\title{
Earthquake Research for the Safer Siting of Critical Facilities
}




\section{DISCLAIMER}

This report was prepared as an account of work sponsored by an agency of the United States Government. Neither the United States Government nor any agency Thereof, nor any of their employees, makes any warranty, express or implied, or assumes any legal liability or responsibility for the accuracy, completeness, or usefulness of any information, apparatus, product, or process disclosed, or represents that its use would not infringe privately owned rights. Reference herein to any specific commercial product, process, or service by trade name, trademark, manufacturer, or otherwise does not necessarily constitute or imply its endorsement, recommendation, or favoring by the United States Government or any agency thereof. The views and opinions of authors expressed herein do not necessarily state or reflect those of the United States Government or any agency thereof. 


\section{DISCLAIMER}

Portions of this document may be illegible in electronic image products. Images are produced from the best available original document. 


\section{DISCLAMMER}

This book was prepared as an account of work sponsored by an agency of the United States Gavernment. Neither the United Siares Governmen: nor any agenc/ thereof, nor any of their employees, makes any warranty, express or implied, or assumes any lejal liability or responsibility for the accuracy. completeness, - or usefuthes of any information, apparatus, product, or process disclosed, or represents that is use would not irfringe privately owned rights. Fefesence herein to a yy specific commercial product, process, or serv ce by trade na ne. irademark, manutacturer, of otheswise, does not necessarily constitute or imply its endorsement, recommendation, or favoring by :he United States Government or any agency thereof. The views and opinions of authors expressed herein do not necessarily state or reflect those of the United States Government or any ogency thereot. 


\section{Earthquake Research for the Safer Siting of Critical Facilities}

Panel on Earthquake Problems Related to the Siting of Critical Facilities

Committee on Seismology

Assembly of Mathematical and Physical Sciences

National Research Council : 
NOTICE: The project that is the subject of this report was approved by the Governing Board of the National Research Council, whose members are drawn from the Councils of the National Academy of Sciences, the National Academy of Engineering, and the Institute of Medicine. The members of the Committee responsible for the report were chosen for their special competences and with regard for appropriate balance.

This report has been reviewed by a group other than the authors, according to procedures approved by a Report Review Committee consisting of members of the National Academy of Sciences, the National Academy of Engineering, and the Institute of Medicine. i

International Standard Book Number 0-309-03082-X

Library of Congress Catalog Card Number $80-82030$

Available from:

Office of Publications

National Academy of Sciences

2101 Constitution Avenue, N.W.

Washington, D.C. 20418

Printed in the United States of America 


\section{COMMITTEE ON SEISMOLOGY}

K EIITI A K I, Massachusetts Institute of Technology, Chairman JOHN C. CROWELL, University of California at Santa Barbara DONALD V. HELMBERGER, California Institute of Technology BR Y AN L. IS ACK S, Cornell University PAUL C. JENNINGS, California Institute of Technology THOMAS V. MCEVILLY, University of California at Berkeley KAREN C. MCNALLY, California Institute of Technology PETER H. MOLNAR, Massachusetts Institute of Technology SVEn TREITEL, Amoco Production Company, Tulsa

\section{Liaison Members}

WILLIAM J. BEST, U.S. Air Force Office of Scientific Research EDW AR D A. FLINN, National Aeronautics and Space Administration WILLIA M W. HAKA LA, National Science Foundation ROY E. HANSON, National Science Foundation JER R Y H A R BOU R, U.S. Nuclear Regulatory Commission GEORGE A. KOLSTAD, Department of Energy JAMES F. LANDER, National Oceanic and Atmospheric Administration MARK E. ODEGARD, Office of Naval Research

CARL F. ROMNEY, Defense Advanced Research Projects Agency JOSEPH 'W. SIRY, National Aeronautics and Space Administration ROBERT E. WA L LACE, U.S. Geological Survey ROBERT L. WESSON, U.S. Geological Survey

Staff JOSEPH W. BERG, JR., Executive Secretary 


\section{PANEL ON EARTHQUAKE PROBLEMS RELATED}

TO THE SITING OF CRITICAL FACILITIES

WILLIAM J. HALL, University of Illinois at Urbana-Champaign, Chairman

CLARENCE R. ALLEN, California Institute of Technology, Pasadena ROBERT G. BEA, Woodward-Clyde Consultants, Houston RAYMOND L. BLUM, Pacific Gas and Electric Company, San Francisco RAY W. CLOUGH, University of California at Berkeley

LLOYD S. CLUFF, Woodward-Clyde Consultants, San Francisco JOHN C. CROWELL, University of California at Santa Barbara JOHN E. LYONS, Exxon Research and Engineering Company, Florham Park, New Jersey

THOMAS V. M CEVILLY, University of California at Berkeley CHRISTOPHER H. SCHOLZ, Lamont-Doherty Geological Observatory, New York

WILLIAM F. SWIGER, Stone and Webster Engineering Corporation, Boston

DA VID D. TILlson, Washington Public Power Supply System, Richland

\section{Liaison Members}

JAMES F. DEVINE, U.S. Geological Survey NORMAN A. DIXON, Office of the Chief of Engineers, Department of the Army

KENT L. GOERING, Defense Nuclear Agency WILLIA M W. HAK A LA, National Science Foundation ROY E. HANSON, National Science Foundation JERRY HARBOUR, U.S. Nuclear Regulatory Commission ROBERT E. JACK SON (J. CARL STEPP), U.S. Nuclear Regulatory

Commission

JOHN F. LANCE, National Science Foundation GEORGE L. SHERWOOD, Department of Energy J. LAWRENCE VON THUN, U.S. Bureau of Reclamation

Staff

JOSEPH W. BERG, JR., Executive Secretary

\section{Technical Editing}

JANET L. CLUFF, Woodward-Clyde Consultants, San Francisco 


\section{Preface}

Earthquakes may affect facilities through strong shaking, sudden fault displacement, ground failure, and tsunami. Earthquake effects pose one set of the many considerations in siting, designing, and building critical facilities; however, this is an important set because the results of an earthquake can be catastrophic. For this reason, the Panel on Earthquake Problems Related to the Siting of Critical Facilities was charged as follows:

To determine what seismologic and geologic information is needed to make decisions for safer siting and construction of critical facilities.

To recommend to public officials, decision makers, and to other concerned people the research program required to provide the needed information.

The focus was on long-term research needs rather than short-term, mission-oriented research. The Panel met several times to address this charge and held a workshop to write a draft of this report. The expertise of the members of the Panel and the workshop participants included engineering, geology, seismology, and other specialties pertinent to the problems. Earthquake research has been recommended herein that will aid in safer siting, as well as provide new information that will aid in the design of critical facilities.

William J. Hall, Chairman

Panel on Earthquake Problems

Related to the Siting of Critical Facilities 
THIS PAGE

\section{WAS INTENTIONALLY LEFT BLANK}




\section{Acknowledgments}

This study was performed by the Panel on Earthquake Problems Related to the Siting of Critical Facilities of the Committee on Seismology in the National Research Council's Assembly of Mathematical and Physical Sciences. The work of the Committee is supported by the Defense Advanced Research Projects Agency, the Division of ProblemFocused Research of the National Science Foundation, the U.S. Geological Survey, the U.S. Air Force Office of Scientific Research, the National Oceanic and Atmospheric Administration, the National Aeronautics and Space Administration, the Division of Earth Sciences of the National Science Foundation, the U.S. Nuclear Regulatory Commission, and the Department of Energy. The Panel wishes to express its appreciation for the interest and support of these agencies. Valuable assistance was obtained from many individuals regarding specific details of the report. 


\section{Contents}

1 EXECUTIVE SUMMARY 1

2 INTRODUCTION 5

3 IDENTIFICATION OF CRITICAL FACILITIES 8

Facilities That May Affect Public Safety or the Environment, 8 Factors That Affect Public Safety or the Environment, 11 Life-Support and Emergency Facilities, 13

Considerations in Siting and Design, 13

4 SITING OF CRITICAL FACILITIES

Statement of the Problem, 15

Suggested Siting Methods, 16

Phase I, 16; Phase II, 17; Phase III, 18; Phase IV, 18

Addressing the "Earthquake Problem," 19

Comments on Experience in Siting of Critical Facilities, 19

5 GEOLOGY AND GEOPHYSICS-MAJOR PROBLEM AREAS 21

Identification and Evaluation of Hazardous Faults and

Earthquake Source Regions, 22

Active Faults versus Tectonic Provinces, 22; Specification of Maximum

Earthquakes, 23; Frequency of Earthquake Occurrence and Degree of

viii 
Fault Activity, 26; Surface Fault Displacement, 27; Microearthquakes versus Macroearthquakes, 29; Artificially Induced Earthquakes, 31

Characterization of Ground Motions, 33

Evaluation of Ground Failure, 34

Evaluation of Tsunami and Seiche, 34

Probabilistic Evaluations, 35

6 BASIC NEEDS FOR EARTHQUAKE RESEARCH

Degree of Fault Activity, 37

Dating of Geologic Materials, 38

Quaternary Processes, 39

Mechanics of the Earthquake Process, 39

Fault and Earthquake Parameters, 40

Historical Earthquakes, 41

Seismic Networks, 41

Earthquake Prediction, 42

Nature of Surface Faulting, 43

Ground Motion, 44

Ground Failure, 46

Tsunami and Seiche, 47

Probabilistic Evaluations, 47

Assessment of Review Processes for Seismic Safety, 48 


\section{Executive Summary}

Strong ground vibration and sudden fault displacement associated with earthquakes can have a catastrophic effect on buildings, industrial complexes, and other structures. It is particularly desirable to avoid earthquake damage to critical facilities, that is, facilities whose failure could seriously affect the public through loss of life, large financial loss, or degradation of the environment. Examples of such facilities are nuclear power plants, nuclear processing and high-level radioactive waste storage and isolation sites, chemical processing facilities, liquefied natural gas terminals, dams, offshore petroleum facilities, pipelines, and lifelines of certain types. Facilities that are required to remain in service following earthquakes to care for the safety or health of the public also are considered critical facilities. Such facilities include hospitals, public safety agencies such as fire and police units, and life-support systems such as waterlines and some highways.

In many cases, the safety of a facility can be enhanced and the potential detrimental effects on the public and the environment can be minimized by careful siting and design. For these reasons, the Panel on Earthquake Problems Related to the Siting of Critical Facilities and its advisors were assembled to review the geologic and seismologic data base available for siting critical facilities and to offer recommendations, particularly of a long-term nature, for improving our ability to site them. To select a site for a critical facility, certain geologic and seismologic parameters must be known, and this knowledge, in turn, can play a role in the design of the facility. Important geologic and geophysical 
problems have been identified by the Panel, and research areas that will help to address these problems are presented as italicized sections of Chapter 6. The following selected recommendations are considered of paramount importance to aid siting.

1. Research should be continued to develop procedures for more accurately assessing the degree of activity of faults. It is important to incorporate the differences in the degree of activity of faults in siteselection procedures because the degree of activity can vary as much as several orders of magnitude from one tectonic environment to another, as well as from one fault to another in the same tectonic environment. These procedures must take into consideration all relevant factors that may be used to estimate how large and how often earthquakes will be on a specific fault. The factors include rupture length of fault, amount of displacement associated with a single event, the slip rate, and the recurrence intervals of earthquakes of various magnitudes.

2. New or improved techniques should be developed for the dating of young geologic materials, because estimating the recurrence rates of faulting and associated earthquakes depends directly on accurate dating. In addition, the history of the faulting will be better understood if increased emphasis is placed on studies of fault-gouge formation, the modification of fault gouge through time, and the possibility of dating constituent minerals.

3. Research of fault behavior, including tectonic model studies; theoretical approaches, and field studies of Quaternary faulting and its relationship to other geologic processes, should be increased. Because there is a lack of understanding of fault development and behavior, many features, such as splay faults, graben, pull-apart depressions, and extension fractures, need to be studied, as these features may provide clues to future faulting.

Additionally, this accelerated program should include the study of the development and time history of physiographic features in less tectonically active areas, such as the Midwest and the east coast of the United States. Even though all earthquakes may not be directly associated with surface faulting, regional deformations may occur that may have an association with crustal faults, and they may help us to understand earthquake mechanisms and seismic sources in these areas.

4. Strong-motion and sensitive seismographic networks should be expanded in the eastern, midwestern, southeastern, and the Great Basin parts of the United States, because we lack the long history and the detailed information that is necessary in the evaluation of earthquake 
mechanisms, particularly in the less seismically active parts of our nation. It is also imperative to maintain and upgrade the present strongmotion networks.

5. Continuing long-term funding for research on seismic ground motions of engineering importance is needed. Both the statistical aspects of the data and the influence of physical factors on ground motions should be studied. This research should address ground motions from moderate to large near earthquakes and large distant earthquakes, the variations of ground motions with different styles of faulting, the variations of ground motions with depth within the upper $30 \mathrm{~m}$ or so below the earth's surface, the relative motions between points separated by distances from several meters to several kilometers on the earth's surface, ground tilts and rotations, and modeling of ground motions. The worldwide installation of strong-motion arrays designed to obtain such data should be supported. Ground-motion data recorded from explosions should be studied to assess their usefulness for earthquakeengineering purposes.

6. Research programs of ground-failure phenomena should be given high priority, because potential for ground failure is often difficult to assess. This includes topics such as the mechanics of liquefaction, differential settlement, lurching, landslides and avalanches, and offshore slope instability. Further, reliable methods of mapping should be developed for identifying and observing areas of potential ground failure. This mapping program should include interpretation of remote-sensing images from satellites as well as conventional methods.

7. There is a need to improve methods of describing earthquake hazards probabilistically so that the uncertainties associated with earthquake safety analyses can be understood and communicated. Decisions regarding earthquake safety should be based on the most accurate information available, and the uncertainties should be identified. In addition, the methods should allow knowledge derived from research and future earthquake occurrences to be applied to the re-evaluation of siting procedures. Research should be directed toward continued development and application of various models of earthquake recurrence, in particular, those that include the phenomenon of clustering.

Chapter 6 contains other important recommendations that have not been discussed in this Executive Summary because the Panel believes that the topics are already receiving attention or because developments can be expected to occur during the natural course of events. These recommendations relate to the following: 
- Laboratory studies of rock failure and measurement of stress and strain in situ.

- Compilation of geologic field evidence of faulting and the effects of future major earthquakes worldwide.

- Research to assess the feasibility of real-time warning of earthquakes by seismic monitoring.

- Research to establish a more comprehensive data base on the effects of historical earthquakes.

- Research to better understand tsunami and seiche mechanisms and their destructive effects.

- Systematic analysis of the various review processes for the seismic safety of all types of critical facilities. 


\section{2 \\ Introduction}

Over the past century, as a result of societal pressures and technological advances, the lifestyles and values of the citizens of the United States and, to a large extent, other industrialized countries in the world, have changed markedly. The task of providing the necessities for living, such as adequate electrical power, water, and fuel, is becoming more complicated with time. Some of the facilities that provide these necessities would present potential hazards to the population if serious damage were to occur to them during earthquakes. Other facilities must remain operable immediately after an earthquake to provide life-support services to people who have been affected. The purpose of this report is to recommend research that will improve the information available to those who must decide where to site these critical facilities, and thereby mitigate the effects of the earthquake hazard.

The term "critical facility" is used in this report to describe facilities that could seriously affect the public well-being through loss of life, large financial loss, or degradation of the environment if they were to fail. Examples of such facilities are nuclear power plants, nuclear processing plants, dams, high-level radioactive waste storage and isolation sites, chemical processing plants, liquefied natural gas terminals, offshore petroleum facilities, and pipelines and lifelines of certain types. The term "critical facility" also is used to refer to facilities that, although they pose a limited hazard to the public, are considered critical because they must continue to function in the event of a disaster so that they can provide vital services. Examples of such facilities are 
hospitals and emergency services (including those on military bases), public safety agencies such as fire and police units, and certain lifelines such as waterlines, communication facilities, and access and evacuation routes.

The problems of selecting sites for critical facilities and obtaining necessary design information to protect the people of an area are many. Further, the problems associated with the siting of many types of facilities are expected to grow dramatically with increasing population, urbanization, an attendant increase in exposure to natural hazards, and a reduction in the number of available sites. Compounding these problems is the distinct possibility that the present energy crisis will cause a sudden flourishing of certain kinds of critical facilities. Among the issues that should enter into siting and design decisions are those pertaining to earthquakes, because devastating damage can be the end result in many cases if appropriate provisions for earthquake effects are not considered.

We do not now have the optimal information base that is required to site all critical facilities to protect the citizens of the United States from the hazards posed by earthquakes-surface faulting, strong shaking, ground failure, and tsunami. As a consequence, many facilities are "overdesigned"; undoubtedly, others are "underdesigned" to resist seismic effects. A goal for our society should be to provide safety from a rationally estimated degree of hazard exposure at any given facility, thereby minimizing the consequences (risk). The state of the art of both siting and earthquake-hazards assessment has advanced considerably over the past decade, and this situation will improve further with time, especially if appropriate research is undertaken.

It can be expected that future requirements for siting critical facilities will be increasingly stringent as a result of public concern for safety and preservation of the environment and increased understanding of the effects of earthquakes. Detailed seismic and geologic investigations of specific sites are expensive and time-consuming. Several millions of dollars may be spent at a site for a dam or a nuclear power plant, of ten over many months to several years prior to beginning construction of the facility. Even so, hindsight indicates that, in some cases, it would have been prudent to have made even more extensive and more timely studies. Millions of dollars have been lost when post-site-commitment geologic and geophysical investigations have resulted in the abandonment of some sites. In other cases, earthquake safety questions have been raised with regard to older facilities sited and licensed under codes and standards that reflected the then-current state of knowledge. Increased understanding of earthquake effects has generally resulted in codes being made more stringent and has caused some facilities to be struc- 
turally strengthened through "retrofitting" or, in a few cases, to be closed down pending resolutions of concerns based on new knowledge.

Even when more advanced criteria are developed and comprehensive evaluations are carried out, direct, definite answers to the questions related to characterization of the seismic hazard and its potential effects may not be achievable. A considerable amount of judgment is required in the development of siting and design criteria. Objectivity by scientists and engineers, especially in the early stages of site selection, is critical to the whole siting process. Professional judgments often introduce the potential for differences of opinion on many technical matters. Recognizing this potential, the goal of the investigator should be to provide sound bases for decisions.

The Panel on Earthquake Problems Related to the Siting of Critical Facilities was established to review the earthquake problems that are inherent in siting critical facilities. Most importantly, the Panel was charged with offering recommendations to public officials and other concerned individuals about research studies, particularly of a longterm nature, that should be undertaken to aid decisions on safer siting. In doing this, geologic and seismologic parame ters that are necessary for the design of the facility (such as ground motions, soil conditions, and maximum earthquakes) have been given special attention. In this sense, the recommendations also will lead to new information that will aid in designing safer structures.

The report presents, in Chapter 3, a brief discussion of various types of critical facilities and some aspects of associated hazards. In Chapter 4 , suggested approaches that might be adopted for safer siting are presented briefly. Some shortcomings in our present-day data base and in understanding earthquake-related problems as they pertain to siting are discussed in Chapter 5. This sets a logical stage for Chapter 6, wherein specific research and study recommendations are spelled out. These research recommendations are aimed especially at upgrading the earthquake safety of future critical facilities through improvements in siting and, to a lesser degree, design procedures. 


\section{3 \\ Identification of Critical Facilities}

\section{FACILITIES THAT MAY AFFECT PUBLIC SAFETY OR THE ENVIRONMENT}

There are at present no well-accepted, definitive criteria for identifying which facilities are critical or, except for a few types, for accurately estimating the potential effects of the failure of a given facility on the public or the environment. In the following sections, facilities that, if they were to fail, would seriously affect the public by causing loss of life or large economic loss or that would seriously degrade the environment are briefly described. Examples of this category are facilities from which toxic or radioactive agents could be released to the air or groundwater, and dams, which could cause inundation by water. These discussions may help to place into better perspective the nature of the facilities and the reasons for concern about their siting.

- Nuclear Power Plants Nuclear power reactors and their inherent radioactivity pose significant potential for dangerous and long-term effects in the event of failure. Because of this potential danger, the facilities are designed to have containment structures and safety systems. Nuclear facility design and construction currently must meet regulatory requirements that are much more stringent than are those for any other type of critical facility. Two important aspects of these regulatory requirements include siting considerations to mitigate seismic effects to the extent possible by existing practices and the requirement for rela- 
tively low-density population in the immediate vicinity of the plant.

- Nuclear Fuel Fabrication The materials used are mostly solids that are only slightly radioactive. Some processes involve liquid phases, which, if released, could enter ground water. Such facilities could pose a moderate danger.

- Nuclear Fuel Reprocessing Reprocessing involves separating spent fuel from reactors into depleted uranium, plutonium, and a variety of fission products (solid, liquid, and gaseous forms), many of which are radioactive to varying degrees. Accordingly, the failure of such a facility could pose a significant danger to the public through air or groundwater dispersion of radioactive materials.

- Long-Term Storage and Isolation of Nuclear Waste The feasibility of storage and ultimate isolation of high-level nuclear wastes from power plants and military operations in deep underground repositories is under detailed study by the Department of Energy. Basically, the goal is to ensure there will be no significant escape of radioactivity. The primary vehicle of transport in the long term is considered to be contaminated groundwater. Accordingly, research is directed primarily toward geologic formations of very low permeability, for example, salt, shale, basalt, and granite masses. It is likely that portions of the waste will be processed into ceramic or glass form or otherwise stored in canisters, thereby decreasing the danger of contamination. The threat to safety could be low to high, depending on site location, type of containment, and the isolation medium.

- General Waste Storage Industrial processes and urban areas generate large amounts of wastes of various types. Many are innocuous, but some result in contamination, most commonly of water sources by leachates. Examples of disposal "facilities" are waste dumps and sanitary landfills; mine, chemical, and other industrial waste products disposal areas; and slag dumps. Regulations usually require provision of low-permeability liner systems or other means of limiting or controlling leachates. In some cases in the past, waste products considered to be of little concern, for example, mercury and $\mathrm{PCB}$, later were found to be toxic or were converted to dangerous materials by natural processes. The storage of wastes of this nature could pose a low to high danger.

- Chemical Processing Plants Petrochemical plants and refineries constitute the largest and most numerous chemical processing facilities. The materials and products are flammable and possibly explosive but generally are not poisonous. Storage is generally in diked tanks so designed that, in the event of tank leakage or spills, the contents will be retained in the diked area and have minimal effect on the environment or on public safety. Damage to structures or piping, as from an earth- 
quake, could cause the release of flammable materials in process areas. These materials could be ignited by process furnaces or other ignition sources.

Plants that manufacture explosives are generally isolated and designed to minimize the effects of an explosion. Safety precautions are well developed and carefully enforced. Thus, such plants pose minimal threats to public safety, provided exclusion areas are preserved.

Plants that manufacture dangerous substances, for example, chlorine, ammonia, or certain other industrial chemicals, may be located in relatively crowded industrial areas. Age and corrosion may render such plants susceptible to damage from earthquakes, and thus they could pose a moderate threat to public safety.

- Dams Dam failures pose a threat to public safety and may result in loss of life, major property damage, and degradation of the environment. Even dams located in remote areas must receive careful attention, because the flood wave may cause damage to facilities and land below the dam for some distance.

The filling of large reservoirs sometimes results in an increase in earthquake activity, a phenomenon commonly termed reservoirinduced seismicity. The triggering mechanism is not well understood, although it appears to be associated with changes in pore pressure along faults beneath the reservoir and the added weight of the water load on the zones of pre-existing stress.

- Offshore Petroleum Facilities Such facilities may comprise drilling, production, and storage facilities. These facilities are designed for large lateral loadings as may be developed by storm winds, waves, currents, soil movements, and ice. Thus, these structures are at least in part inherently resistant to earthquake forces. The direct danger to the general public from failure of of fshore petroleum facilities is normally small. Damage to the environment may be significant, depending on local ecologic factors and the amount of spill of petroleum.

- Underground Storage of Petroleum and Petroleum Products Present plans for underground storage of crude petroleum are to use solution-mined caverns in salt domes and certain existing mines; future caverns also could be in granitic rock. Fortunately, in the United States, most favorable salt domes and mines currently under consideration are located in areas of apparently low seismicity. These caverns would be inherently stable against even large seismic events, provided they are located away from active faults.

Liquefied petroleum gases (LPG), such as butane and propane, in many cases are stored under pressure in subsurface caverns in salt domes, granitic rock, and dense sedimentary rock. In other cases, they are stored above ground in containers. 
When stored in subsurface caverns, the current practice is to design rock caverns so that groundwater pressures exceed liquefaction pressures of the LPG to inhibit migration of the LPG into the formation. Care is taken to select dense rock having minimal fracturing or joints and to place caverns at depths such that joints are tight to minimize groundwater seepage into the cavern. Although caverns are relatively stable, local roof collapse near shafts or between the cavern and shafts, or rupture of piping, could occur, especially during severe earthquakes.

The gases are heavier than air, and in all cases a potential danger exists from fire and explosion. The threat to public safety would be greater for above-ground storage in earthquake-prone areas. In the same context, natural gases are stored in sedimentary rock for peak-demand purposes. These facilities pose a lesser danger; however, their siting also needs careful consideration.

- Liquefied Natural Gas Terminals These terminals consist in part of heavily insulated cryogenic tanks at low pressures and supporting refrigeration and regasification units. Liquefied natural gas (LNG) is concentrated in storage tanks, and the potential danger centers around tank or pipeline rupture and a release of contents.

In its liquefied state, LNG is neither flammable nor explosive; it must be vaporized and then mixed with air before it can burn. Tanks are placed in diked areas of adequate volume to retain liquid contents but not the vapor. Density currents of cold gas or gas-air mixtures may flow some distance from a ruptured tank before becoming warm enough to become lighter than the ambient air. Proposed standards of safety for design of LNG facilities have been issued by the Department of Transportation and are being reviewed. The threat to public safety of LNG terminals could be high, depending on such factors as the degree of isolation.

- Pipelines Pipelines are subject to damage primarily from fault rupture if they cross an active fault, from landslides, and from strong ground motions. Telescoping or tensile failures of buried pipelines from ground motion have been noted following many earthquakes. The degree of threat to public safety derives principally from the contents of the pipeline and the volume of material.

\section{FACTORS THAT AFFECT PUBLIC SAFETY OR THE ENVIRONMENT}

Listed below are examples of the types of factors that enter into the evaluation of the potential threat to public safety as a result of earthquake damage to a critical facility. 
- Energy Available for Release Large energy release in the event of failure can greatly increase dispersal of contaminants or increase mechanical damage.

- State of Contaminant The state of the contaminant on dispersal materially affects the danger. Solids in large masses would travel only limited distances. Liquids may travel much longer distances, and paths would be confined and determined by topography, river flow, or groundwater conditions. Fine particulates or aerosols may be carried long distances by air currents. Gases lighter than air would rise into the atmosphere and eventually disperse; heavier-than-air gases may travel substantial distances and accumulate in low areas or depressions, where they may remain relatively undispersed for some time.

- Mode of Transmission Transmission may be direct and immediate as, for example, when a toxic or explosive gas is released or when flood water issues from a breached dam. Secondary transmission includes such conditions as contamination by leachates or concentration by biological processes, as through the food chain.

- Size of Area Affected Some effects may be confined to the immediate vicinity of the event. Obviously, the larger the area, the greater the potential effects, assuming equal population distribution and equal concentration or toxicity.

- Predictability of Area Affected The potentially affected area may be readily predictable as, for example, the area subject to inundation in the event of gross failure of a dam. For other events, the area affected may depend on wind velocity and direction or other meteorological conditions, and limits can only be estimated.

- Character of Effect Several factors can characterize the effect such as (a) toxicity, including concentration or amount of ingestion or inhalation necessary to produce deleterious effects or death; (b) radiologic effects; (c) mechanical effects, such as drowning, destruction by erosion, flotation, inundation, or fire.

- Persistence The persistence of the contaminant refers to the longterm toxicity (or half-life, if radioactive).

- Detectability Some contaminants, such as radioactive materials, are readily detectable, whereas others are not. This factor is important in isolating or decontaminating an area or in tracing leachates or other secondary modes of dispersal.

- Duration of Effects The effects may be short term, as where flooding occurs without erosion, or long-term, as where fertile farm lands are washed away or are covered by sterile sands or gravels in the event of dam failure. Also to be considered is long-term contamination that cannot be reduced to safe levels and may have long-term or permanent effects on the plant and animal life of a region. 
- Evacuation Protection of the public by evacuation must consider total population potentially affected, the time available between an incident and the time when it begins to affect the public, as well as the ramifications (cost, logistics, security, psychological effects) of such activity.

\section{LIFE-SUPPORT AND EMERGENCY FACILITIES}

Other critical facilities that require special siting considerations are those whose failure poses a limited threat to public safety but that are required to remain in service after an earthquake to care for the wellbeing of those affected. These facilities include hospitals; certain highways; communication networks; pipelines necessary for potable water and for fire fighting; and police, fire-fighting, and emergency aid facilities. Accordingly, siting and design should be such as to ensure continued function in the event of earthquakes.

High-occupancy buildings, such as schools and high-rise buildings, also may be considered to be critical facilities. Some military support facilities, such as hospitals and firehouses, also have been critical facilities historically for disaster relief and, therefore, should receive earthquake siting considerations.

\section{CONSIDERATIONS IN SITING AND DESIGN}

The foregoing discussions indicate that a great many types of geologic, geophysical, and geotechnical considerations should enter into the siting and overall design of critical facilities. Consideration must be given to earthquake-related effects due to strong ground shaking; surface faulting; ground failure (including terrestrial and submarine landslides, subsidence, uplift, and liquefaction); differential ground motion; stability of caverns and tunnels, seiche, and tsunami; and factors such as geologic and soil conditions at the site.

It should be recognized that there is a difference between potential hazards and perceived hazards. In some cases, the potential hazard can be controlled by the care and conservatism used in site selection and design, especially when based on accurate geologic and geophysical investigations, recognition of potential modes of failure, provision of safety margins, avoidance of hazardous sites, and isolation of the facility or process. Care and conservatism in siting and design have not been consistently employed in the past because the hazards have been judged to be higher or lower than is realistically the case because of a lack of knowledge and understanding. This results in a perceived hazard, which may be different for different judges of the same facility. 
There is no uniform approach for evaluating the susceptibility of different types of facilities to damage from earthquakes. Extensive research is being conducted throughout the world in the area of probabilistic hazard assessment. In time, as probabilistic approaches are developed and uncertainties about earthquake hazards are reduced, it may be possible to evaluate seismic exposure on a more reasonably uniform basis by using statistical probabilities.

At present, because of the many uncertainties in the existing geologic and geophysical data base for most parts of the nation, extreme caution must be exercised when using the results of most computer-produced earthquake risk analyses that are becoming available. The Panel believes that at this time statistical probabilistic analyses should be used for insight rather than for numerical results. 


\section{4 \\ Siting of Critical Facilities}

\section{STATEMENT OF THE PROBLEM}

There are no generally accepted methods or approaches that are common to the siting of all critical facilities. At present, nuclear facility siting must meet regulatory criteria and requirements that are, in general, considerably more restrictive than those for other critical facilities. For some critical facilities, such as dams, liquefied natural gas (LNG) plants, and hospitals, governmental agencies are in the process of developing siting criteria and regulations. Other critical facilities have no seismic safety siting requirements. Also, in some parts of the country (for example, California) and within some federal agencies (for example, the Veterans Administration), the earthquake safety issue receives much more attention than in the remainder of the United States and within other governmental agencies. This lack of consistency in siting causes some segments of society to be exposed to higher seismic risks than are others.

The major factors that contribute to inconsistent seismic exposure are (1) differing degrees of seismic hazard from location to location, (2) differing levels of knowledge about the location and degree of seismic activity of geologic structures that generate earthquakes, (3) differing levels of understanding of earthquake hazards and acceptance of seismic risk from one place to another, (4) differences in the state of the practice in the siting of different critical facilities, (5) lack of public awareness about earthquake hazards, and (6) an absence of generally defined levels of acceptable earthquake risk. 
New techniques and approaches for evaluating earthquake hazards are being developed; however, with a few exceptions they are at present not incorporated into the general siting practice. As techniques are refined and improved methods of earthquake hazard evaluation are implemented, earthquake sources can be more realistically described. Siting criteria and regulatory controls might then be tailored more appropriately to each class of facility to effect reasonable and balanced hazard-reduction efforts consistent with the degree of fault activity and the level of risk acceptable to society.

\section{SUGGESTED SITING METHODS}

A procedure for siting critical facilities should provide a mechanism for balancing the many factors that must be considered in selecting a site. Moreover, it should be requisite for any procedure to accommodate new knowledge as it becomes available and to reflect lack of knowledge where it exists. Some examples of factors that must be considered in the location of sites are potential hazards, population density, water, transportation, transmission, markets, governmental regulations, pollution, materials, functional needs, aesthetics, economics, labor, public acceptance, capital, and competitors.

It is the opinion of the Panel that factors relating to earthquake effects and public safety should be high on the list of site-selection factors for all critical facilities. Geologic studies aimed at identifying and evaluating active faults should be conducted before the site-selection process is completed. Presence of active faults may require the selection of an alternate site or further detailed studies to assess the degree of fault activity and the potential for surface fault rupture, ground failure, strong ground motion, tsunami, and induced seismicity. In some cases, it may be desirable to develop techniques and special designs for accommodating fault displacement. A suggested procedure for siting critical facilities, which is aimed at evaluating the earthquake hazard, follows.

\section{Phase I}

(a) On the premise that a need for the facility has been established, define the type and size of facility and the required physical space for the facility and its appurtenances. Preliminary planning at this stage may include consideration of economic feasibility and preparation of a tentative design and construction schedule. 
(b) Define a region or regions of interest where siting studies are to be conducted.

(c) Define siting criteria, including constraints. These usually include, but may not be limited to, the following considerations and/or requirements:

Geology

Seismicity

Geotechnical considerations (foundation)

Existing regulations, licensing, and permit requirements (including siting, public health, and environmental laws)

Population density and dispersion

Water requirements and availability

Hydrogeology

Topographical or bathymetric considerations

Transportation and access requirements (fuel and materials delivery)

Transmission or pipeline requirements (proximity to markets)

Environmental considerations (a wide range of factors, for example, rare and endangered species)

Socioeconomic considerations

Interrelationship with other, existing critical facilities

(d) Reject obviously unsatisfactory areas.

Once the siting criteria, which may or may not be "weighted" at this stage, have been identified, studies may proceed as follows.

\section{Phase II}

(a) Perform office studies, including map and literature searches and interpretation of aerial photographs of the regions of interest.

(b) Record and document gathered data on transparent map overlays (or computer grids), for example, potential geologic hazards, known faults, linear features, and epicentral locations of past earthquakes. Map scale for this phase may be $1: 250,000$ to $1: 1,000,000$.

(c) Obtain needed new data for the region, for example, remotesensing imagery, bathymetric data, base maps.

(d) Perform first-order screening using siting criteria overlays to the basic data maps, eliminating clearly unacceptable areas.

(e) Identify optimum candidate siting areas within the regions of interest based on the pre-established siting criteria. Candidate areas can range from several tens to several hundreds of square miles in size.

(f) Plan Phase III studies, including obtainment of access rights to perform various field studies in the candidate areas. 


\section{Phase III}

(a) Refine (increase) the scale of the basic data maps and photographs. Map scale for Phase III studies may be 1:24,000 to 1:62,500.

(b) Perform field investigations of unresolved linear features previously identified on aerial photographs or other remotely sensed images.

This task is part of fault identification studies that may require much broader regional geologic studies aimed at describing the tectonic environment.

(c) Perform various field studies, including environmental and geologic mapping aimed at the identification of potential hazards.

(d) Perform sufficient exploratory drilling and trenching to construct rough stratigraphic profiles through potential sites in the candidate areas.

(e) Evaluate the groundwater regime and characteristics (may require piezometers at potential sites).

(f) Record and document on transparent map overlays (or computer grids) new information on $1: 24,000$ to $1: 62,500$ scale base maps.

(g) Based on the new field information and generally more detailed studies, screen or contour candidate areas in to optimum subareas or, if possible, candidate sites, eliminating clearly unacceptable areas. In other words, as the quantity and quality of data increase, there should be an ongoing effort to identify candidate sites optimized to the original siting criteria. Candidate sites may range in size from 1 to perhaps 20 square kilometers.

The level of Phase III studies will vary with the physical complexity of the candidate area; type of critical facility; federal, state, or local regulatory constraints; amount and quality of data regarding earthquake hazards; and other factors. In most cases, however, the level of studies should be sufficient to permit a meaningful ranking of several candidate sites, even though the quality of the existing data results in various levels of uncertainty. Methods of ranking or rating sites can range from simple numerical (value judgment) matrix systems to more sophisticated decision analysis approaches, including "trade-off" concepts.

\section{Phase IV}

The purpose of Phase IV studies is to focus more detailed studies to reduce the uncertainties at a selected candidate site to the extent that it meets all the siting criteria previously identified or the siting problems are recognized. A single "preferred" site should be identified at this 
point in the process, and the extremely detailed and costly Phase IV studies should be applied only at the preferred site.

(a) Perform de tailed, site-specific mapping, drilling, trenching, testing, and sampling to complete technical licensing and design requirements, including assessing the degree of activity of any faults.

(b) Estimate maximum earthquakes as required, in terms of source, magnitude and/or intensity, recurrence interval, characterization of resultant ground motion at the site, and potential for induced seismicity, surface fault rupture, and tsunami or seiche.

(c) Complete any other required earthquake and foundation engineering studies, for example, ground failure, including liquefaction potential, and soil-structure interaction.

(d) Prepare documentation to be submitted in support of facility licensing or to address permit requirements.

\section{ADDRESSING THE "EARTHQUAKE PROBLEM"}

The "earthquake-problem" aspects of the critical facility siting process are addressed in all phases and may be quickly reduced to a few basic tasks. These may be simplistically stated but often are difficult to achieve:

(a) Identify significant faults in the study region.

(b) Assess the degree of activity of each fault in terms of both surface fault rupture and earthquake-generation potential. Evaluating the recency of fault displacements and estimating recurrence intervals are essential to accomplish a measure of the degree of activity of a fault.

(c) Assess the ground-motion attenuating or amplifying potential of earth materials between the earthquake-generating faults and the site.

(d) Consider all the earthquake hazards: surface fault displacement, strong shaking, ground failure, tsunami, and seiche. Achieve the desired level of safety through a combination of (1) siting, (2) eliminating hazards by removing or correcting hazardous conditions, and (3) designing to accommodate the hazards.

COMMENTS ON EXPERIENCE IN SITING OF CRITICAL FACILITIES

It is the opinion of the Panel that a comprehensive geologic and seismic data base must be developed so that early decisions regarding earth- 
quake hazards can be reached with a high degree of confidence. Such a data base should allow an early input to the siting process rather than be viewed as a necessary formality after site identification, purchase, or other commitment. This will involve two acts to arrive at a more satisfactory site selection: (1) commitments to research such as that described in Chapter 6 of this report and (2) following a rigorous and rational siting investigation program such as that outlined earlier in this chapter. The importance of these two acts cannot be overemphasized. The costs of geologic and seismologic investigations as an integral part of the site-selection process are indeed small when compared with the costs related to resolving a controversy after a commitment has been made in selecting a site.

The timing and adequacy of seismic and geologic considerations in the siting process are extremely important. There are numerous examples of critical facility siting controversies centered around the uncertainty as to the characteristics of the seismic hazard. These controversies have occurred over planned and existing nuclear power plants, major dams, pipelines, hospitals, and other facilities, some of which have been constructed but have been or are now being subjected to costly (millions of dollars) delays in final licensing or granting of permits. In other cases, reassessment of the earthquake hazards based on emergent technological advances has caused extensive and costly design modifications and "retrofitting" to critical facilities in the construction stage.

Hindsight indicates that some of these expensive controversies could have been mitigated (or possibly even avoided) had an adequate geologic and seismic data base been developed and used during the planning process. In any case, the costs to society have been large in dollars, energy-generating capacity, and services.

In view of the length of time required for the design and construction of critical facilities, it often happens that new information becomes available or changes are made in regulations before the facility is operational. Differences of opinion often center around the importance of observed or inferred geologic and seismic factors. The impact on the original hazard assessment can be lessened if these factors are anticipated and an adequate data base is established. Carefully planned siting investigations that include the collection and interpretation of geologic and seismic data, coupled with information acquired through long-term research efforts, play an important role in resolving controversies over safety to the public and to the environment. They also contribute to the economic feasibility of a project and provide essential information for design of the facility. 


\section{5 \\ Geology and Geophysics - Major Problem Areas}

The many controversies that have arisen over the past few years concerning the earthquake safety of proposed critical facilities have dramatically emphasized the deficiencies in our geologic and geophysical understanding of earthquakes. Major gaps exist in our knowledge of seismic phenomena, and nowhere is this better illustrated than in attempts to specify the locations, frequencies, and maximum sizes of future earthquakes that might affect critical facilities-the questions of "where," "how of ten," and "how big"? Seldom can all three of these questions be answered with anywhere near the confidence that we desire. As a result, some structures with deficient resistance have undoubtedly been built; although probably more often critical structures have been built using excessive conservatism to compensate for our acknowledged ignorance. Improved answers to these questions should, therefore, serve not only to increase our confidence in the safety of critical structures, but this knowledge should also permit such structures to be built more economically, without the waste that is necessarily inherent in overconservatism.

In this chapter, some of the major geologic and geophysical problems that are present in the siting of and setting of design standards for critical facilities are discussed; in Chapter 6 , research that will contribute to the solutions of these problems is recommended. 
IDENTIFICATION AND EVALUATION OF HAZARDOUS FAULTS AND EARTHQUAKE SOURCE REGIONS

\section{Active Faults versus Tectonic Provinces}

Central to the siting problem for critical facilities is the need to identify locations at which future significant earthquakes may occur. The techniques currently used in this effort differ markedly in the eastern and western parts of the United States.* Major controversies revolve around each of these techniques, as well as around attempts to formulate a more universally applicable procedure. It is generally agreed that virtually all large earthquakes are caused by sudden displacement on faults at varying depths. However, not all damaging earthquakes have occurred on faults that obviously extend to the ground surface or on faults of regional extent. Earthquakes may occur on faults that are not easily recognized, especially in the eastern United States. Thus, different techniques for assessing earthquake hazards have evolved in the eastern and western United States.

In the western United States, essentially all damaging earthquakes have been associated with displacements on faults that could have been been recognized prior to the earthquakes on the basis of surface exposures. Furthermore, most of these faults are sufficiently active that similar displacements have occurred repeatedly during late Quaternary time (past several thousand years), leaving geologic clues of various types. In the eastern United States, however, faults may not be recognizable from surface exposures, and identifying and evaluating such features may be exceedingly difficult. Nevertheless, it is important to recognize that earthquakes throughout the United States, whether in the East or West, are the result of slip on faults. That these faults are more obvious in the West is related to a number of factors: (1) the degree of fault activity is much higher in the West, thus there are more abundant clues; (2) erosion and sediment deposition rates are higher in the East than the fault slip rates, so evidence is soon obliterated after an earthquake; (3) in large parts of the East, particularly in glaciated areas, there is an absence of surficial deposits suitable for assessing fault activity; (4) the dense vegetative cover in the East may conceal faults that would otherwise be obvious; and (5) some of the tectonic processes that localize faults and earthquakes in the East may be different from those typical in the West.

Because of the difficulty in recognizing active faults in the eastern

"In this report, the boundary between eastern and western United States is taken as the eastern front of the Rocky Mountains. 
United States, it is generally the practice to use the "tectonic province" approach for estimating seismicity, rather than to assign hy pothetical maximum earthquakes to specific faults, as is done in the West. In estimating vibratory ground motion under the tectonic province approach, the largest earthquake that has occurred historically anywhere within a tectonic province is assumed to be capable of occurring any where else in the province; individual faults are not usually considered. The definition and recognition of the boundaries of tectonic provinces are, however, subject to great differences of opinion, and, in the opinion of the Panel, the technique must be improved and eventually changed. Boundaries between tectonic provinces have traditionally been defined on the basis of old geologic structures, and these may or may not have any relevance to earthquake-producing mechanisms of today.

It is the opinion of the Panel that; although at present the tectonic province approach may be the only practical method for siting critical facilities in parts of the eastern United States, in the long run, we must work toward a procedure for the East that is similar to that used in the West-one that is based on identifying individual geologic structures responsible for earthquakes. If this work is to produce results soon, there is an urgent need for increased research leading to (1) a better understanding of ongoing tectonic processes in the eastern United States, such as has resulted from studies in the areas of New Madrid, Missouri; Charleston, South Carolina; and New England; (2) a more complete definition of the seismicity and geology of the eastern United States through more extensive instrumental and field observations, which should include measurements and evaluations of in situ stress;

(3) a correlation of seismic activity with ongoing tectonic processes; and (4) better theoretical approaches, such as model studies of tectonic processes that are at work in this intraplate region. Recognizing the very low level of seismicity in the East, significantly greater geologic and geophysical efforts probably will be required than in the West, almost certainly involving new and innovative techniques.

\section{Specification of Maximum Earthquakes}

After a causative fault has been identified, a variety of methods, procedures, and terminology has been used to specify the maximum earthquake to be associated with that fault. Such events have been called the "maximum credible earthquake," "maximum expectable earthquake," or, with regard to special facilities, "safe-shutdown earthquake" or simply the "design earthquake." None of these terms has been precisely defined in a usable way, and what is "credible" or "expectable" to one 
person may not be to another. For example, is an earthquake of the magnitude that might statistically occur once in every million years "credible" or not? Ideally, the maximum earthquake should be defined on some sort of probability basis, and the maximum acceptable risk for the project should be arrived at independently; final judgment of the earthquake safety should be made only after the two independent contributions have been considered, along with the earthquake behavior of the structure under construction. In practice, few builders of critical facilities specify the acceptable risk; some admit no risk at all! Even if the risk were specified, geologists and seismologists usually do not have sufficient data for many areas on which to assign confidently the maximum earthquake on a rigorous probability basis. More often than not in present practice, the concept of the maximum credible or maximum expectable earthquake has some intrinsic elements of both scientific probability and acceptable risk. In the opinion of the Panel, this is not a satisfactory long-term state of affairs; efforts must be made to separate the evaluation of the scientific likelihood of a potentially disastrous event from the assignment of the risk that society is willing to accept for a particular critical facility.

The danger in assigning a maximum earthquake that is too small is obvious; the structure is apt to fail disastrously during an event that is larger than was assumed in the siting and design. The danger in assigning an earthquake that is too large, however, is not so obvious; it is the cost to society of building a wastefully expensive structure or perhaps of not building it at all. An assigned maximum earthquake for one structure is likely to affect subsequent designs in the same region.

The maximum earthquake is typically chosen as the kind of event that might statistically be expected to occur once every few thousand or tens of thousands of years, although on major active faults such as the San Andreas, the maximum event might occur more of ten. This very rarity of the event, seldom having happened within the historical record, makes it difficult to evaluate and quantify. Current techniques for estimating maximum earthquakes fall into four categories, none of which is free from major interpretive problems and controversies.

1. In areas of active faulting, the most commonly used method is to estimate the maximum earthquake from the length of the causative fault. It is mechanically impossible for a large earthquake to be generated on a fault of small length, and, from world wide data of historical earthquakes, one can see a rough correlation between fault rupture length and earthquake magnitude. Often the assumption is made, again based on historical observations, that one half the total length of a fault 
can break during a single slip event, and this half-length is then compared with the lengths of observed ruptures during historical events of known magnitudes. The regression analyses of observed length-magnitude data, however, show great variance; uncertainties in a specific magnitude determination can be large. Without an analysis of the possible errors, there is a clear danger in placing too much confidence in a result just because it appears "quantitative."

2. From exposures of faulting, it is sometimes possible to estimate the amount of displacement associated with individual prehistoric earthquakes. Just as there is a rough correlation between magnitude and fault length, a similar rough correlation exists between magnitude and displacement, the largest displacements clearly being associated with the largest earthquakes. Again, however, the variance is large, and only limited confidence can be placed in conclusions derived from a specific exposure. A special problem with earthquakes in the magnitude 5 to 6 range is that many such events have been associated with no observed displacement, but the regression analyses have usually included only positive data and thus are biased in this magnitude range.

3. Particularly in areas lacking active faults, the historical record of earthquakes in the region may be one of the few clues to future events. The longer the history, the better will be the statistical base for an extrapolation. However, even those parts of the world having the longest histories, such as Japan and China, show considerable inhomogeneity in the statistical pattern of earthquake occurrences in both space and time. Although it is tempting to apply sophisticated statistical techniques to limited data, extreme caution must be used in estimating maximum earthquakes from the historical record alone, particularly if that record is as short as it is throughout the United States. History has shown the folly of assuming that the largest earthquake a region has experienced in the recent past is necessarily representative of the maximum event in the future.

4. If adequate instrumental (seismographic) records of earthquakes are available in a given region, some clues as to the nature and frequency of large events can be extrapolated based on statistical analyses of these data. However, there are great pitfalls in simplistic attempts to use this technique, as discussed in the section of this chapter titled Microearthquakes versus Macroearthquakes.

In actual practice, the final assignment of the maximum earthquake is usually based on a combination of several of these techniques, with the judgment of the geologist or seismologist playing a key role. Because of the inadequacy of the basic data, the decision is often an exceedingly difficult one, and it is not surprising that many honest differences of 
opinion have resulted in individual siting cases. Often, for professionals associated with the proposers of a critical facility, there is an inclination to assign a maximum earthquake that is on the low side, thereby reducing the cost and perhaps ensuring continued project viability. The probability of an earthquake occurring during the lifetime of the engineer or scientist is too low to act as an automatic check against underestimating the risk. For professionals on the outside, there is an inclination to specify a maximum earthquake that is on the high side. This provides comfort and confidence to the scientist or engineer because of the extremely low probability of such an event occurring. This also leads to difficulty in arriving at reasonable engineering design parameters. The geologist and seismologist involved in a seismic study must scrupulously resist pressures either for or against a particular site that arise from arguments other than those directly related to earthquake safety. It is equally important that the uncertainties in the estimate of the maximum earthquake be addressed. In the opinion of the Panel, the rigid adherence to true professionalism and scientific integrity by the geologist and seismologist is an important factor in arriving at solutions to seismic siting-problems.

\section{Frequency of Earthquake Occurrence and Degree of Fault Activity}

Closely related to the problem of assigning the maximum earthquake is the problem of specifying how of ten it or smaller events will occur. If the maximum earthquake is deemed sufficiently unlikely, for example, a particular facility may be designed for a somewhat smaller but more frequent event. In other instances, two levels of earthquakes are accommodated; the facility is designed to withstand the maximum earthquake in a "safe shutdown" or containment mode, with some acceptable level of damage that is repairable. The second level of design provides that the facility remain functional during the smaller, more-frequent events. Frequency of earthquake occurrence has normally been estimated by two techniques: (1) As was discussed in the preceding section, extrapolations can be made from historical and instrumental records of past events, but with many debatable assumptions concerning homogeneity of the data. (2) By geologic field studies of the recent evidence of fault displacement, using radiometric or other dating techniques on displaced or disturbed strata, conclusions can sometimes be drawn regarding the recurrence intervals between past earthquakes. The latter technique has been shown to be particularly useful in studies in the West and in the Mississippi Valley, where recurrence intervals of large earthquakes on given segments of major faults have been estimated.

By long tradition, geologists have typically deemed faults "active" or 
"inactive" depending on their judged hazard, which is usually based on an estimate of the recency of displacement. With the advent of formal siting controversies, these words, as well as related terms such as "capable" and "incapable," have tended to take on rigid legal definitions that perhaps have done more to obfuscate the cause of hazard reduction than to aid it. The problem is that rigid definitions do not allow the degree of fault activity to be taken into consideration, and once a fault is classified as "active" according to these definitions, it becomes equally as hazardous as any other active fault. Such is not a correct description of nature.

A comparison of fault-activity rates between faults associated with different tectonic environments and even faults within the same tectonic environment shows that there can be a difference of several orders of magnitude in the degree of activity of different faults. As an example, a given fault in a highly active tectonic environment may have an average slip rate of $6 \mathrm{~cm}$ per year and may have the potential for as much as $10 \mathrm{~m}$ of displacement in a single event. The recurrence interval for the 10-m slip event may be 150 years. Conversely, a fault in a tectonic environment of low activity may have an average slip rate of $0.0006 \mathrm{~cm}$ per year and may have the potential for only $24 \mathrm{~cm}$ of slip in a single event. The recurrence interval for the $24-\mathrm{cm}$ slip event may be 30,000 years. Both faults may be of engineering concern for critical structures, but it is absurd to class them together under the term "active" as if they were of comparable hazard. It is the Panel's opinion that we must work toward the phasing out of terms such as "active," "inactive," "capable," and "incapable" as rigid, legalized descriptions that tend to categorize a fault as safe or unsafe. Instead, we must aim toward specifying the degree of activity of individual faults on a quantitative basis. Whether or not a given fault is acceptably safe, or should be considered in the design of a critical structure, is a function not only of the degree of activity but also of the ability of the facility to accommodate that amount of slip, as well as the level of acceptable risk for the particular facility.

\section{Surface Fault Displacement}

Surface fault displacement may become a problem when a critical facility is built or is planned to be built across a fault sufficiently active that surface displacements are considered credible. Although surface faulting has historically caused only minor total damage as compared with that caused by the associated strong ground shaking and it is often disregarded in the design of noncritical facilities, surface fault displacement through a dam, for example, might endanger an entire city. The maximum fault displacements observed at the ground surface during 
recent historical earthquakes are $10.7 \mathrm{~m}$ vertically (India, 1897) and $8.9 \mathrm{~m}$ horizontally (Mongolia, 1957); they were associated with two of the largest earthquakes. However, for the great majority of fault breaks, the maximum displacements have been less than 5 or $6 \mathrm{~m}$. The average displacement along a fault length usually has been less than 50 percent of the maximum. Shallow-focus earthquakes of magnitude 6.0 and greater in the western United States, excluding parts of Alaska and the Puget Sound area, have usually been associated with surface fault rupture. All 16 shallow-focus earthquakes larger than magnitude 6.5 that have been reasonably well investigated in the field have been associated with surface faulting. In every case, faulting occurred along fault zones that had histories of earlier displacements, usually within Holocene time. Findings of studies of earthquakes outside the United States are consistent with this observation.

When the selected area for a critical facility is in a geologic environment containing hazardous faults, it is necessary to evaluate the potential for surface fault displacement so that provision can be made in the design of the structure to accommodate it or the planned facility can be sited away from the fault. If the facility is of a lifeline type (pipeline, bridge, freeway, transmission line), and must cross the fault, the structure can often be designed to accommodate the expected relative displacement, or, at the least, contingency plans can be made for timely repair.

The problem of surface faulting has frequently been neglected unless a known hazardous fault exists at the site. The general procedures for the selection of sites for critical facilities have not always included an evaluation of the potential for surface faulting, although this situation is rapidly changing. Even where such studies have been carried out, there are often major shortcomings in their scope: (1) Sometimes investigations focus almost entirely on the historical earthquake record and pay little attention to the geologic record of fault activity. (2) There has been a reluctance to carry out the regional and broader tectonic studies that are necessary for the evaluation of the faulting potential at the site. It is naive to assume that all the relevant evidence can come from the site itself, yet this has often been a matter of some controversy. (3) There has been an unfortunate tendency to rely on previously published geologic studies that were conducted without the objective of looking for evidence of fault activity. A factor contributing to inadequate seismic hazards assessments is that new techniques and approaches recently developed to assess fault activity have not always been incorporated into the general practice of site evaluations for critical facilities. In some cases, this has resulted in the untimely identification of active faults where none was previously thought to exist. 
All too often, specific sites for critical facilities have been selected that quickly become subject to firm financial, political, and psychological commitments prior to geology and seismicity studies. Admittedly, the sites of some types of structures such as dams are not easily adaptable to change, and many factors other than earthquakes play a dominant role in site selection. However, the Panel believes that one of the most important contributions to the realistic and economical siting of critical structures is the early evaluation of the seismic hazard, including that of surface faulting, prior to the time that firm commitments are made to a specific site. This is particularly true for the western part of the United States, where there is an abundant history of commitments for critical facilities that have run afoul of earthquake-related controversies that might have been avoided by better planning that included early regional geologic and seismic studies of earthquake hazards.

\section{Microearthquakes versus Macroearthquakes}

In all parts of the world, even regions of very low seismicity, small earthquakes occur more frequently than large earthquakes. The relationship, in fact, is a systematic one, usually with about ten times as many earthquakes of a given magnitude occurring as compared with those of one magnitude unit higher on the Richter scale. That is, if ten earthquakes of magnitude 2 are recorded during a given day in a particular area, on the average, one earthquake of magnitude 3 may be recorded and, if the instruments are sufficiently sensitive, 100 earthquakes of magnitude 1 . The actual ratio varies from place to place and from time to time and is the subject of considerable research interest in itself, but the important point is that by recording very small (or "micro") earthquakes for a short period of time using very sensitive instruments, one might extrapolate from these data to infer the recurrence interval between the large ("macro") earthquakes that are of engineering concern. Thus, microearthquake recording instruments are often placed in areas where one is attempting to evaluate long-term seismic hazard. There is no formally accepted dividing line between microearthquakes and macroearthquakes, although it is often arbitrarily considered to be at about magnitude 3 .

If one follows the simplistic tenfold empirical relationship outlined in the preceding paragraph, the same area characterized by ten daily earthquakes of magnitude 2 would, by simple extrapolation, expect a magnitude 8 earthquake about once every 300 years. Thus the seismic hazard problem might seem to have been neatly solved by a single day's recording! Such techniques have, in fact, had great value in seismicity 
evaluations, but two major problems are apparent: (1) the extrapolation gives no clue as to the maximum earthquake that is possible in the area (a magnitude 8 event in this tectonic setting might be totally unreasonable, and (2) there is the necessary assumption that the short period of recording is statistically representative of the longer period for which the extrapolation is made. This assumption is clearly wrong in many situations (for example, the area of a temporal "seismic gap" or within an aftershock sequence), and thus the technique must be used with great caution. It could be a window to past events through aftershocks, rather than a projective device for the future. Extrapolations of this type may sometimes be valid and of considerable benefit in estimating long-term seismicity, but major problems remain in determining under what conditions they are valid and under what conditions they are not.

Quite aside from temporal extrapolations, the recording of microearthquakes may have great value in revealing relevant information about local geologic structure. For example, sensitive seismometers may, in a few months of recording, show the alignment of hypocenters along a fault, the existence and activity of which would take many years of recording by normal instruments to document. Similarly, focal mechanisms that delineate local structural patterns or stress fields may be obtained from dense microearthquake networks. Major interpretive problems are present here, too. For example, although the presence of aligned hypocenters seems to demonstrate adequately the existence of an active fault, the converse is not always true; many parts of the very active San Andreas fault show essentially no microearthquake activity, apparently because of local locking mechanisms that prevent strain from being released except during infrequent great events. Furthermore, although the presence of microearthquakes may indicate that a fault is active, they say little about the degree of activity or the size of possible maximum events. In fact, parts of the San Andreas fault zone that have the most microearthquakes are zones that are currently experiencing tectonic creep and thus might be incapable of generating truly great earthquakes.

Therefore, in summary, the recording of microearthquakes represents an intriguing and valuable tool in the evaluation of seismic hazard, because many more events can be analyzed in a short time than is possible using traditional seismic networks. The Panel emphasizes that great caution must be exercised in interpreting the data; simplistic extrapolations can be dangerously misleading. Major problems remain in understanding the relationships between large and small earthquakes. 


\section{Artificially Induced Earthquakes}

After several surprises in recent years, most geologists and seismologists now agree that some earthquakes have been artificially induced or triggered. Earthquakes have been triggered by underground fluid injection and extraction, by large underground explosions, and by the filling of reservoirs. In the context of the siting of critical facilities, the last of these mechanisms is the most important, because in at least two of the generally accepted cases of reservoir inducement (Koyna, India, and Xinfengjiang, China), the triggered earthquakes have been large enough to cause significant damage to the dams impounding the newly filled reservoirs. From the geologic and seismologic points of view, two major problems remain unsolved: (1) What is the mechanism by which reservoir-induced earthquakes have occurred? (2) Why have earthquakes been triggered by some reservoirs and not by others?

The subject of reservoir-induced earthquakes was the topic of a report, ${ }^{*}$ and the subject has continued to grow in interest because of the subsequent documentation of several more suspected cases. Although the field is one of controversy, there seems to be general agreement on a few points: (1) Moderate to large induced earthquakes represent the triggered release of tectonic strain and are not the sole result of the stresses imparted by the water load or the weakening of the fault zone; that is, the reservoir is only the triggering agent for an earthquake that almost would be capable of happening anyway. (2) Only a small portion of reservoirs is suspected of having induced earthquakes. Out of a world wide population of some 11,000 significant reservoirs, it has been estimated that there have been approximately 45 accepted and 25 questionable cases of reservoir-induced seismicity. (3) The largest induced earthquakes have generally been associated with deep and large reservoirs, although some of the deepest reservoirs have reported no induced activity, and some shallow reservoirs have triggered small to moderate events.

There is no general agreement on the particular conditions that are conducive to reservoir-induced seismicity, other than those mentioned above. Earthquakes have been induced in a wide variety of geologic and tectonic environments, and nearby reservoirs in the same geologic environment have sometimes shown widely disparate induced seismicity.

*Joint Panel on Problems Concerning Seismology and Rock Mechanics, Earthquakes Related to Reservoir Filling, National Academy of Sciences, National Academy of Engineering, 1972, 24 pp. Available from National Technical Information Service, Springfield, Va., PB-208 327. 
At present, we cannot identify with confidence those areas where induced earthquakes are particularly likely or unlikely. The four most significant events, between magnitudes 5.8 and 6.5 , all occurred in reservoirs having water depths of $80 \mathrm{~m}$ or greater, and there are approximately 300 to 500 reservoirs of this size in the world. Even if a strictly statistical approach is used, a probability of 4 out of 300 is not so small that it can be ignored by designers of high dams.

The prejudice of most geologists would probably be that reservoirinduced seismicity is more unlikely in stable areas than in areas of highly active tectonism, particularly those having large active faults and numerous earthquakes. However, the largest accepted reservoirinduced event (Koyna, $M=6.5$ ) occurred in an area of the Indian Precambrian shield that has many of the attributes of a relatively stable area. A somewhat isolated Holocene fault was subsequently identified in the area, probably representing the causative structure, and there is a growing but not yet convincing body of evidence that most large reservoir-induced earthquakes have occurred in areas having at least some pre-existing active faults. All the larger events have occurred outside the United States, and, in most cases, the local geology has not been well documented in the literature. In at least one case (Koyna), surface faulting was associated with the induced earthquake, so surface faulting as well as vibratory ground motion must be considered by engineers facing this problem.

Considerable debate has taken place as to the cause of reservoirinduced earthquakes, but no consensus has emerged. The two most likely triggering mechanisms are (1) stresses caused directly by the weight of the water and (2) increased pore pressures as a result of the filling. Adequate instrumentation has not as yet been emplaced at any one reservoir to study the physics of the system, and several recommendations along this line are given in the discussion of research needs in Chapter 6. There is some indication that induced events can be at least partially controlled by the rate of filling.

In the Panel's opinion, the importance of the problem of reservoirinduced earthquakes cannot be overestimated. Millions if not billions of dollars are now being spent to design large dams resistant to reservoir-induced earthquakes around the world, even in areas of low historical seismicity. It will undoubtedly turn out that much of the expenditure was unnecessary, because the areas are not prone to induced events. But until we know how to recognize these areas with confidence, we have no choice but to be exceedingly conservative in the design of large dams, almost regardless of the level of historical seismicity. 


\section{CHARACTERIZATION OF GROUND MOTIONS}

When an earthquake occurs, complex ground motions in the form of seismic waves propagate away from the source in all directions. The ground motions may be recorded at a station where instruments have been installed. Typically, these instruments record displacement, velocity, or acceleration (primarily acceleration in the case of strong ground motions) as a function of time. Analyses of these data, complemented by studies of the physics of the earthquake process and wave propagation, have led to a limited understanding of the nature of ground motions in recent years. More detailed knowledge of the characteristics of these motions is desirable for engineering design applications.

The first moderate- to strong-motion accelerographs were designed and installed in 1932, in time to record the first strong-motion accelerograms during the 1933 Long Beach earthquake. The number of installed accelerographs has grown over the years; with the realization of the importance of such data, the rate of growth has increased markedly, and, at present, it is estimated that approximately 5000 instruments are installed worldwide. Even so, the statistical base of ground motion data is extremely limited.

The selection of sites for placement of strong-motion accelerographs has traditionally been made primarily by engineers interested in the earthquake response of buildings and other major facilities. As a result, most instruments are concentrated near major population or industrial centers, and the remaining instruments are spread sparsely throughout the seismically active zones of the world. Few instruments have been deployed in integrated arrays designed for the purpose of gaining detailed information about the generation, transmission, and local modification of strong ground motion.

In the design of critical structures and facilities, after the design earthquakes have been selected, it is necessary to estimate the ground motions that are to be used in design. The ground motions that are estimated typically include the transient peak accelerations, velocities, and displacements; the duration of strong shaking; and, in some cases, the frequency content. At present, these estimates are subject to considerable uncertainties, reflecting the limited historical data base and the lack of detailed, quantitative knowledge of the influence of physical factors on ground motions. Data are particularly limited for near-field and large-magnitude earthquakes; unfortunately, such events pose the greatest hazard to structures. 
There are several aspects regarding the details of ground motions for which data are generally lacking. These aspects, which are of great importance in the design of structures, include the variation of ground motions with depth below the surface (important for deeply embedded structures such as nuclear power plants); the relative motion from point to point on the ground surface (important for the design of long structures such as bridges and pipelines); and the torsional and tilting motions of the ground.

\section{EVALUATION OF GROUND FAILURE}

Ground-failure phenomena that have been observed during earthquakes include liquefaction, differential settlement, lurching, landslides and avalanches, and of fshore slope instability. These effects are the result of a combination of strong shaking, the physical properties and extent of surface deposits, and depth to groundwater. The mitigation of the destructive effects of ground-failure phenomena is simply a matter of siting to avoid areas where ground-failure potential exists, correcting the problem by removing or changing the characteristics of the susceptible deposits or designing the foundation of the structure to accommodate the hazard. The primary problems in the evaluation of groundfailure potential are (1) the current lack of understanding of the mechanics of ground-failure processes and (2) the inability to predict confidently whether and to what extent ground failure may occur.

\section{EVALUATION OF TSUNAMI AND SEICHE}

Tsunami (seismic sea waves) are generated in the ocean by large off shore earthquakes. The mechanism for tsunami generation is thought to be rapid vertical displacement of a part of the ocean floor as a result of offshore fault displacement and associated tectonic uplift and deformation. In the open ocean, tsunami are characterized by long wave length (hundreds of kilometers), long periods of oscillation (from five to several tens of minutes), high velocities (up to about $1000 \mathrm{~km}$ per hour), and low wave height (no more than about a meter). Some of these characteristics change significantly with encroachment of tsunami along the coastline; namely, the velocity diminishes and the wave height increases as the water shoals. The approach of tsunami is usually indicated by water withdrawal or flooding followed by a series of wave surges. Some surges have attained heights in excess of $30 \mathrm{~m}$. Recorded tsunami surge heights of $15 \mathrm{~m}$ are not uncommon. When these devastating waves have struck a populated coastline, entire villages have been swept away and 
major critical industrial facilities have been destroyed. The devastating power of seismic sea waves is well documented. Within the past 200 years, more than 300 damaging tsunami have been recorded, causing extensive devastation and killing tens of thousands of people in a single event. Earthquake-triggered landslides along coastal areas have caused local run-up as high as $540 \mathrm{~m}$.

The local height of a tsunami is affected by several variable factors that include (1) directional characteristics between the tsunami source and the stricken coastline; (2) shape and orientation of the source (type and geometry of seafloor fault displacement); and (3) coastal characteristics that involve refraction, diffraction, reflection, and resonance (all of which are involved in run-up and drawdown of the water). The wave height may be amplified or attenuated significantly over short distances along a given coastline exposed to tsunami hazards. Our present ability to estimate accurately whether a specific location along a coastline may be exposed to a tsunami hazard varies greatly from place to place, even along the same stretch of coast. Also, the type and effectiveness of protective measures are not well understood. These uncertainties require future research to enable us to understand the variable factors so that critical facilities can be safely located in coastal areas where there is the potential for tsunami activity.

In inland areas, ground motions may produce long-period waves (seiche) in bays, lakes, and reservoirs. These are often the results of long-period vibrations generated by distant earthquakes that may be imperceptible to persons at the site. Overtopping of an embankment by seiche caused by settlement of the crest during strong ground motions, water-level changes resulting from landslides into a reservoir, or displacement of the reservoir bottom are problems that need to be considered in the siting and design of dams. Other critical facilities having proposed lakeshore sites could be subjected to the hazards of seiche.

\section{PROBABILISTIC EVALUATIONS}

Deterministic, yes-no answers regarding earthquake safety (hazards and risks) are becoming decreasingly useful, particularly with regard to evaluating the safety of critical facilities. Nothing is absolutely safe, and there are many uncertainties involved in the many aspects of earthquake safety. Therefore, there is an increasing need to communicate accurately the various levels of uncertainty that are associated with each step in the many steps involved during earthquake hazard evaluation. This is particularly important for critical facilities, where the consequences of failure cause the various professionals engaged in each step 
of the evaluation process to add extra conservatism that of ten compounds to cause overconservatism resulting in unreasonably costly design for some facilities. On the other hand, lack of knowledge may lead to some facilities being sited in much more hazardous environments than those for which they were designed and constructed.

The most common model suggested to represent earthquake occurrences is the Poisson model, which assumes spatial and temporal independence of all earthquakes. However, the evaluation of the Quaternary geologic evidence for seismicity, combined with the historical record of seismicity, shows that significant earthquakes exhibit nonrandom patterns in terms of location, size, and frequency of occurrence. The occurrence of significant earthquakes can be represented by a relatively continuous, gradual process of strain accumulation, interrupted periodically by episodes of sudden energy release caused by fault slip. Several factors influence the size and frequency of earthquakes in a given area: the area available to accumulate strain, the rate of strain accumulation, the shearing resistance along faults, and the amount of sudden fault displacement. This physical model suggests a dependence of earthquake occurrence on at least two conditions: the size of the most recent significant earthquake and the time elapsed since this earthquake. Since both conditions will vary from fault to fault, the probability of occurrence of a significant earthquake can be expected to vary from location to location, even within the same tectonic region.

Complete statistical treatment of earthquake recurrence must take into consideration the fact that the earthquake process is one of gradual strain accumulation interrupted periodically by sudden fault slip. Resulting probabilities of occurrences of different magnitude earthquakes in a given zone during a specified period of interest should be locationand time-specific, that is, dependent on the initial condition of the zone and applicable for the duration of real time.

The continuing research in refinement of probabilistic models, together with the potential of incorporating geologic data on the degree of fault activity, should allow a more realistic assessment of earthquake hazards that could result in a better quantification of seismic risk. A crucial missing parameter in such calculations is an estimate of the state of stress in the rocks at the earthquake source region. 


\section{Basic Needs for Earthquake Research.}

In Chapter 5, the major geologic and geophysical problems in the siting of critical facilities were outlined. This chapter addresses the research areas in which emphasis must be placed if these problems are eventually to be solved. No simple one-to-one relationship exists between specific problem areas and specific research programs, because many of the more basic research areas are relevant to several of the problems, and many of the problems will be solved only by simultaneous attack from several different directions of research. It should be pointed out once again that the approach herein emphasizes the solution of fundamental problems by long-term research not short-term studies that may be necessary for specific sites or specific facilities. Each section that follows includes italicized statements that describe specific research requirements.

\section{DEGREE OF FAULT ACTIVITY}

One of the most important questions that needs to be answered is: What is the degree of activity of not only the faults that will be discovered in the future but the active faults that are currently known and mapped? The criteria that have been developed over the years have tended to create the general impression that all active faults are equal, when, in fact, we know there is a wide range in the degree of fault activity from one active fault to another. The frequency of occurrence of damaging earthquakes along one fault may be one every 100 years 
or so, while on another active fault, the recurrence interval may be many hundreds of years, and, on yet another active fault, the recurrence interval may be tens to even hundreds of thousands of years. Clearly these differences in the degree of fault activity affect the probability of a damaging earthquake occurring, and these differences must be incorporated into the overall evaluation of seismic safety for critical facilities. Further research needs to be undertaken to develop procedures wherein the degree of activity of a fault can be taken into consideration, based on the length of fault rupture, the amount of displacement associated with a single event, the slip rate, and the recurrence intervals of various-magnitude earthquakes.

\section{DATING OF GEOLOGIC MATERIALS}

In estimating the probability of future earthquakes at a given locality, of ten the only clue is the geologic record of earthquakes that have happened in the recent past, deforming or displacing strata, coastal terraces, or other geologic "markers." For example, experience has shown that those faults that have slipped most often in the recent geologic past are the ones most likely to slip again in the near future; trenches excavated across faults of ten reveal strata that have been displaced repeatedly during prehistoric earthquakes. Quantitative extrapolations of the actual degree of hazard are possible only insofar as one can estimate the dates of past events, which in turn depends on the dating of geologic materials such as soils or buried strata by methods that have usually employed geochemical radiometric techniques. The most relevant materials for hazard evaluation are the geologically very young ones, generally less than one million years old, and it is in this age range that most existing radiometric techniques are not adequate. One of the most important contributions to the evaluation of seismic hazard would be the development of new or improved techniques for the absolute dating of very young geologic materials, techniques that are more convenient, more accurate, and less costly than those currently available. Examples of research topics include better understanding of chemical rate processes such as desert varnish, leaching, various weathering reactions, further work on the complexities of amino acid racemization, and the differential selection of trace elements and cosmic-ray products as delineated by the study of isotope geology.

Many faults are characterized by the presence of narrow zones of highly crushed and altered rock resulting from repeated displacement of the fault during its history. This material, of ten called "fault gouge," might include mineral elements whose dates of formation or modifica- 
tion would give important clues to the history of displacement on the fault. Thus, studies of the mechanism of fault-gouge formation, the modification of fault gouge through time, and the possibilities of dating fault gouge appear particularly promising. To date fault gouge, a better understanding is needed of pressure-temperature conditions, mineral phases, and clay mineralogy. To date the most recent displacement in fault gouge, research is needed on how the mineral fabric is affected by fault displacement.

\section{QUATERNARY PROCESSES}

Just as it is essential to be able to assign absolute ages to very young rocks, it is important to understand the processes that have been modifying the earth's surficial geologic environment during the past two or three million years, the Quaternary Period. For example, the dating of recent displacements on many faults depends on observations of whether they cut surficial soils, yet we have only limited knowledge of the rates at which soils form under various climatic and geologic conditions. Similarly, some active faults such as the San Andreas have displaced physiographic features such as stream channels, but, unless we have knowledge about the natural rates of channel erosion and landscape modification, we can say little about exactly how active the fault has been and may: be in the future. Even in areas where earthquakes may not be directly associated with surface faults, regional deformation may occur, such as the warping of coastlines. It is critical to understand how surficial features develop and how they change with time.

\section{MECHANICS OF THE EARTHQUAKE PROCESS}

Until we understand fully the mechanics of fault displacement, fault behavior, and, thus, the mechanics of the earthquake-producing process, we shall never be able to predict with confidence the types of earthquakes that are possible or likely at a given locality. For example, the role of groundwater in the faulting process remains incompletely understood, yet it must play an important role in reservoir-induced earthquakes, as well as in earthquake swarms, aftershock sequences, and probably all types of seismic activity. Similarly, faults clearly break under stress, yet we have only limited knowledge of the actual stress conditions within the earth's crust or of the stress conditions that are necessary to fracture various types of rocks in their natural environments. Important research areas for these problems are laboratory studies of rock failure, as well as the development of more effective 
means of measuring stress and strain in situ. One of the most important steps for estimating relative seismic hazard would be the development of a practicable means of routinely and repeatedly measuring absolute stress in the earth's crust at the depths at which earthquakes typically occur. Also important is the measurement of strain over wide areas of the earth's surface by geodetic means. Some current research programs in this area using satellites or extraterrestrial light sources, such as very-long-baseline interferometry, look promising. In the long run, our aim should be to locate those areas for the sites of critical facilities where the stresses at earthquake depths are sufficiently low or the strains are changing so slowly that significant fault displacements are unlikely. Furthermore, it should be our aim to describe quantitatively just how unlikely these displacements may be.

\section{FAULT ANDEARTHQUAKE PARAMETERS}

As was pointed out in Chapter 5 , one of the few clues to the maximum magnitude of an earthquake that might occur on a given fault is the total length of the fault. Based on observations of historical faulting, together with regional geologic mapping, a rough correlation is seen to exist between these two parameters, but we clearly need many more observations to develop a really satisfactory correlation. In particular, we need to examine more carefully the geologic field evidence associated with major earthquakes wherever they may occur, especially outside the United States, where many events relevant to U.S. problems have received only cursory attention. Are there other parameters that might be more effective than fault length in judging the maximum earthquake expected on a given fault? How "repeatable" are earthquakes from one event to the next at a given locality? Can more effective methods be found to evaluate fault displacements during individual prehistoric earthquakes and therefore provide clues as to what might be typical of extreme events in the future? Further attention also must be given to the geologic effects of large earthquakes aside from surface faulting, such as widespread soil liquefaction, which may reflect heavy shaking during prehistoric earthquakes. The importance of such studies cannot be overemphasized; almost all sites for critical facilities have one or more faults in the vicinity, even in the eastern United States, yet the specification of the largest-magnitude event that might occur on such faults has almost always become a matter of controversy, simply because of our present ignorance of the parameters that control or reflect earthquake magnitudes. 


\section{HISTORICAL EARTHQUAKES}

Many of the controversies over the siting of critical facilities have concerned the nature and extent of strong ground shaking associated with historical earthquakes near the sites. Much of the seismologic effort in siting studies has been in the search of historical records for detailed descriptions of long-forgotten earthquakes. Particularly in the eastern United States, most of these earthquakes predate the installation of seismographs, so the only descriptions are in terms of macroscopic effects-the damage and other visible and perceptible consequences. Usually these reports have been used to assign the degree of shaking at various localities, using the modified Mercalli (M M) scale of intensity, which necessarily substitutes for the magnitude scale prior to about 1900 and for many small events even thereafter. The facts that so much effort has been put into historical searches and so many controversies have resulted therefrom testify to the inadequacy of our current data base on historical earthquakes. This is an area in which further research is needed, particularly directed toward the establishment of a more homogeneous and nationwide data base of the effects of historical events. An allied need is for more effective means of converting historical reports and $\mathrm{MM}$ intensities to quantitative engineering parameters.

\section{SEISMIC NETWORKS}

Aside from geologic field observations of faulting and deformation associated with large historical earthquakes, virtually every thing we know about the occurrences of earthquakes comes from the instrumental seismographic networks that have been developed since about the turn of the century. Such networks fall into two categories: those of a global nature that are sufficiently widespread to record earthquakes on a worldwide scale and networks that are designed to give information on specific sites or regions. Both play an important role in hazard evaluation.

It might be questioned why the recording of earthquakes in China or the South Pacific is relevant to the understanding of earthquake problems in the United States, but one must remember that really large earthquakes are comparatively rare, even on a global scale. A large proportion of our knowledge about the nature and engineering effects of damaging earthquakes, about which we are concerned in the siting and design of critical facilities, comes from earthquakes that have occurred elsewhere in the world. Thus, in recent years, the United States has 
sponsored the Worldwide Standardized Seismographic Network (WW SSN) of some 120 widely spaced stations, and data from this network have contributed immensely to our understanding of earthquake mechanics, plate tectonics, and regional seismicity. Because of its international scope, support for the WW SSN has been difficult to maintain, but it has contributed so much to our fundamental knowledge of earthquakes, including many aspects directly relevant to the siting of critical facilities, that its continued operation could be defended on that basis alone.

Regional and local seismographic networks, such as the currently operative 160-station array in southern California, a major array in Utah, and an array in New England, serve some of the same research purposes as the WWSSN and additionally provide direct information on the seismic hazard of specific areas within the United States. Certainly, the presence of earthquakes in a given area over a period of a few years does not directly correlate with long-term seismic hazard from large earthquakes, and long-term seismic hazard cannot in any known way be assessed solely from even the most sophisticated of seismic networks, but the information is nevertheless relevant and necessary. The densest current networks are, logically, in the regions of highest seismicity and highest hazard, but the Panel recommends an expansion of seismic detection capability (strong-motion and sensitive seismograph networks) into the less-active parts of the country, where the risk is low but not negligible and where our current understanding of the earthquake mechanisms and hazard is less satisfactory than in more earthquake-prone areas such as California.

\section{EARTHQUAKE PREDICTION}

A major scientific effort to predict earthquakes, apart from estimating recurrence intervals, is currently under way in the United States, as well as internationally. In many ways, this effort toward accurately predicting earthquakes (when, where, and how big) is not directly applicable to siting critical facilities with a 50- or 100-year life. Furthermore, no matter how accurately an earthquake is predicted, the prediction itself, in most cases, will not prevent damage to a structure that is poorly sited, poorly designed, or poorly constructed.

On the other hand, an accurate prediction can markedly facilitate the safe operation of some kinds of critical facilities by allowing temporary shutdowns, restricted operations, or drawdown of reservoirs. For example, a nuclear reactor might be shut down during the period of an earthquake prediction, and, in this sense, the prediction effort has a direct bearing on the safety of critical structures. In addition, if a reliable and 
accurate prediction capability can be achieved, this will allow structures such as nuclear reactors to be sited in seismic areas with the confidence that additional safety measures could be taken during times of imminent seismic danger. At the moment, such a procedure must be regarded only as a very distant hope, but the time may come when areas such as those close to the San Andreas fault zone in California can be utilized for siting some types of critical facilities that must now be placed elsewhere.

Somewhat related to earthquake prediction is a recently proposed early-warning system, whereby the first-arriving $\mathrm{P}$ waves at stations close to the epicenter of a large earthquake might be used to alert more distant localities of the imminent arrival of the damaging vibrations. Such a system would, of course, permit only a very brief warning, about 30 $\mathrm{sec}$ at $200 \mathrm{~km}$, for example, but even this might be valuable for automatic shutdowns of certain types of critical facilities. Whether sufficient reliability could be achieved in such a system to permit its routine use is problematical, as is the question of whether an adequate market exists to justify the expense. The Panel believes that the real-time warning of earthquakes warrants further research attention. From the point of view of siting, this system might encourage the choice of sites appropriately located with respect to potential earthquake sources to give the maximum warning time.

\section{NATURE OF SURFACE FAULTING}

In the western United States, there are many controversies concerning the nature of surface faulting that might pass through the specific site of a critical facility. To what degree will the faulting be limited to a pre-existing narrow trace? Are new branch faults and splay faults possible? Just how wide will the rupture zone be, and what will be the nature of ground displacement within that zone? Is extension as well as shearing possible? Answers to these questions have thus far depended on a combination of detailed geologic mapping at the specific site and the results of observations of the effects of large earthquakes elsewhere. The problem is worthy of more general study. In areas where the faulted rigid basement is overlain by a thick cover of alluvium or young sediments, the stresses that account for near-surface deformation operate in quite different directions from those at depth, where the driving force for the deformation derives. Thus, surficial features are developed such as splay faults, graben, pull-apart depressions, en echelon folds, Riedel shears, and extension fractures. The Panel believes there is no question but that our understanding of surface faulting features and how they might affect a given site could be enhanced by further model studies, 
theoretical approaches, and field studies of historical and Quaternary faulting and its relationship to other geologic processes.

Studies of tectonic style associated with particular tectonic settings are now appropriate, in part as an outgrowth of the theory of plate tectonics. Plate movements are primarily responsible for crustal deformation, and the orientation and types of faults and folds in the terrane beneath critical facilities reflect these movements. In California, for example, many of the active faults and folds have orientations typical of simple shear along a transform (strike-slip) plate boundary. Old faults in the same terrane, oriented so that the modern resolved shear stress upon them is not an optimum, are not likely to slip in the present stress regime. Studies of the orientations and strain release roles of faults and folds in different types of tectonic settings are therefore desirable.

\section{GROUND MOTION}

In spite of the present relatively large amount of data available, the bases for estimating seismic ground motions are still rather tenuous. Accordingly, it is recommended that a continuous base of funding be provided for research on seismic ground motions of engineering importance, with emphasis on the statistical aspects of the data, the influence of physical factors on ground motion characteristics, and an understanding of the characteristics of the wave motions that constitute the ground motions.

At present, almost no information is available pertaining to strong ground motions at depths below the ground surface, and additional information of this type should be procured as rapidly as possible. Such information would be of particular importance if it could be procured as part of an array that would permit study of the nature of the wave propagation under near-surface conditions to a depth of $30 \mathrm{~m}$. There is a need to improve our understanding of the nature of the wave-transmission mechanisms that occur, which in turn would enable us to verify the applicability of various models that have been and are being developed for estimating such near-surface motions.

A detailed study of strong-motion earthquake instrument arrays was undertaken in 1978 as part of an international study, ${ }^{*}$ and a summary of some findings of that study follows:

*Strong-Motion Earthquake Instrument Arrays, Proceedings of International Workshop on Strong-Motion Earthquake Instrument Arrays, May 2-5, 1978, Honolulu, Hawaii, W. D. Iwan, ed., sponsored by the National Science Foundation and UNESCO, issued by the California Institute of Technology, Pasadena, California, 1978, 103 pp. 
Ample promising sites exist for the deployment of dense strong-motion earthquake instrument arrays.... There are a number of sites for which there appears to be a very high probability of obtaining useful strong-motion data within 10 years.

There is an adequate understanding of the nature of earthquake ground motion to be able to design useful strong-motion arrays which will provide answers to some of the important unresolved questions facing the designers of structures and other facilities in the earthquake-prone regions of the world... .

The cost of deploying strong-motion arrays, although great, is not excessive considering the magnitude of the benefit to be derived from such deployment.

The Panel recommends that the worldwide installation of strong-motion networks be supported. Additionally, it is imperative to maintain and upgrade the present strong-motion network.

Recent studies clearly indicate that a limited amount of ground-motion data exist for sites close to fault zones; there is a pressing need to obtain additional such data. These data will help to clarify the dependence of near-source ground motions on the size of the earthquake and the characteristics of the ground medium. For example, in some cases, for very strong ground motions, there probably is a limited acceleration level that can be transmitted through certain types of soil.

There also is limited information available about more systematic ground motions occurring at greater distances from large earthquakes as, for example, the motions associated with surface waves. This field of knowledge is becoming increasingly important as long-period systems are constructed (high-rise buildings, dams, offshore platforms, large storage tanks, mechanical systems). Ground motions from large distant earthquakes need further study and definition for engineering applications.

Other important areas needing better definition are those pertaining to relative motion and tilt and rotation of the ground at points and over distances of several meters to several kilometers. Many engineering structures spanning significant lengths, for example dams, pipelines, and bridges, are dependent in their design, in part, on knowledge of the relative motions between two points. Almost no time-synchronized groundmotion data exist at present from which such relative motions can be estimated, and a program to acquire such data needs to be pursued with vigor.

A significant amount of ground-motion data have been generated by high explosives and nuclear testing. These have characteristics that are, in many cases, quite similar to those from earthquake sources. Groundmotion data from explosions should be examined in the light of possible 
applications to earthquake engineering. This area of research, with distinct possibilities for technology transfer, should be pursued with attention to such factors as energy release, peak ground-motion parameters, wave propagation and attenuation characteristics, relative motions, and scaling of amplitudes.

In recent years, major advances have been made in the physical understanding and analytical modeling of fault rupture, wave propagation through the geologic media from the earthquake source to a site, and local wave propagation in the site soils. A reliable analytical method for calculating ground motion directly from a geologically realistic fault model would aid immeasurably in reducing the uncertainty that currently arises when one infers ground motion from magnitude, which in turn has been inferred from fault length. Such analytical methods need to be continuously tested and calibrated using recorded data from strong earthquakes.

\section{GROUND FAILURE}

Research of ground-failure phenomena, including liquefaction, differential settlement, lurching, landslide and avalanche, and offshore slope instability, is needed. Ground-failure effects have been a major cause of damage during past earthquakes and pose considerable potential for damage to critical facilities during future earthquakes. For example, during the Chinese Tangshan earthquake in 1976, where several hundred thousand persons lost their lives (casualty estimates range from 240,000 to 750,000 ), severe ground failure effects extended over an area of more than $3000 \mathrm{~km}^{2}$. Ground-failure reportedly caused 70,000 wells and 40 pump stations to be lost, $500 \mathrm{~km}$ of railroad and $228 \mathrm{~km}$ of highway to be seriously damaged or destroyed, and $800 \mathrm{~km}$ of river embankments to be destroyed. Failures do not occur at random; they are limited and related to certain geologic and hydrologic settings and to certain types of deposits. A threshold of strong shaking is required to induce ground failure.

Reliable methods need to be developed for mapping areas of potential ground failure or where conditions may be favorable for the development of ground-failure phenomena. Maps need to incorporate age, type, mode of origin, and physical characteristics of sedimentary deposits, groundwater depth, and expected exposure to strong ground shaking of the delineated zones. Research on landslide susceptibility is needed to refine the interrelationships of slope gradient, topographic form, lithologic characteristics, and groundwater conditions. Maps need 
to be developed, utilizing these data together with the potential for strong ground-motion exposure, to show areas that have a high potential and probability for landslide occurrence. Programs are needed wherein explosions are used to study the effects of pore-pressure increases and the susceptibility of landsliding resulting from generated ground motions. Continuing research is needed on the use of penetration devices for the evaluation of liquefaction potential. Improved models of soil behavior and analytical procedures need to be developed for predicting earthquake-induced deformations in natural soils and in earth dams.

\section{TSUNAMI AND SEICHE}

Because it is necessary to site critical facilities along waterfron ts that may be susceptible to tsunami and seiche effects, there is a need to better understand the tsunami and seiche mechanisms and their destructive effects. In particular, there is a need to know more about wave radiation patterns and their relationship to the source mechanism (threedimensional tectonic displacement of the seafloor). Also, along affected coastlines, there is a need to study the effect of local topographic and geometrical coastal configurations as they relate to amplification and attenuation that involve wave refraction, diffraction, reflection, resonance, energy dissipation, and drawdown and run-up phenomena. More accurate and reliable methods are needed to estimate the potential effects of tsunami and seiche action, as well as reliable methods and measures to protect critical facilities.

\section{PROBABILISTIC EVALUATIONS}

There is a need to develop methods of describing earthquake hazards probabilistically so that the uncertainty associated with each step of the earthquake safety analysis can be understood and communicated. Public-policy decisions regarding earthquake safety should be based on the most accurate information available, and the uncertainties should be identified.

In addition, the methods should allow knowledge derived from research and future earthquake occurrences to be applied to the reevaluation of siting procedures. There is a need to establish a common probabilistic framework that allows new data to be taken into consideration when they become available.

It is important to understand that confidence in probabilistic results is directly related to the ability to understand the fundamental aspects 
of earthquake mechanisms and fault behavior. Scientists must face earthquake safety issues knowing that there are uncertainties and attempt to quantify the uncertainties probabilistically so that value judgments about the level of acceptable risk are based on the best and most reliable data at the time of the decision. There is a need for a mechanism for giving the most accurate answer now, while periodically revising estimates as more reliable data become available, so that decision makers have a realistic basis for earthquake hazard mitigation and risk management. An adequately completed probabilistic approach allows scientific assessments to be made with a clear indication of the degree of confidence in the data.

\section{ASSESSMENT OF REVIEW PROCESSES FOR SEISMIC SAFETY}

It is recommended that a periodic review be made of the various safety criteria used in assessing the seismic safety of all types of critical facilities. There is a need to assess the adequacy of the existing safety criteria and to identify where such criteria may need to be improved or when new ones may need to be established. 


\section{APPENDIX \\ Workshop Participants}

CLARENCE R. ALLEN, California Institute of Technology, Pasadena ROBERT B. BEA, Woodward-Clyde Consultants, Houston JO SEPH W. BERG, JR., Executive Secretary, Committee on Seismology RAYM OND L. BLUM, Pacific Gas \& Electric Company, San Francisco JA NET L. CLUFF, Woodward-Clyde Consultants, San Francisco LLOYD S. CLUFF, Woodward-Clyde Consultants, San Francisco JOHN S. CROWELL, University of California at Santa Barbara JAMES F. DEVINE, U.S. Geological Survey NORMAN A. DIXON, Office of the Chief of Engineers, Department of the Army

KENT L. GOERING, Defense Nuclear Agency WILLIAM J. HALL, University of Illinois at Champaign-Urbana JER R Y HA R BOU R, U.S. Nuclear Regulatory Commission JOHN A. KELLEHER, Woodward-Clyde Consultants, Clifton,

New Jersey (formerly with the U.S. Nuclear Regulatory Commission) JOHN F. LANCE, National Science Foundation JOHN E. LYONS, Exxon Research and Engineering Company,

Florham Park, New Jersey THOMAS V. MCEVILLY, University of California at Berkeley CHRISTOPHER H. SCHOLZ, Lamont-Doherty Geological Observatory, New York

GEORGE L. SHERWOOD, Department of Energy WILLIAM F. SWIGER, Stone and Webster Engineering Corporation, Boston

DA VID D. TILLSON, Washington Public Power Supply System, Richland

M. NAFI TOKSOZ, Massachusetts Institute of Technology, Cambridge J. LAWRENCE VON THUN, U.S. Bureau of Reclamation 
